\title{
A View of Research on English Polysemous Phrasal Verbs*
}

\author{
LU Zhi \\ Guangdong University of Foreign Studies, Guangzhou, China \\ SUN Juan \\ Ningbo University, Ningbo, China
}

\begin{abstract}
Phrasal verbs, accounting for a large proportion in modern language, pose numerous challenges to foreign language learners of English, who usually view verb + particle combinations random. The issue of unpredictability is obviously a problem for English learners. Making things worse, many phrasal verbs are polysemous. For one thing, one phrasal verb may have multiple meanings; for another, several phrasal verbs may have the same or similar meanings. While the fast development of cognitive linguistics theory provides a new perspective for the study of English polysemous phrasal verbs. Researchers apply cognitive linguistic theory into second language acquisition and find that the multiple senses of phrasal verbs are actually systematic and motivated. The present study summarizes studies of polysemous phrasal verbs from the perspective of traditional approaches and cognitive approaches as well as the empirical studies based on it and analyzes the shortage of traditional approaches on phrasal verbs. Lastly, this paper illustrates some drawbacks of empirical study based on the assessment of Boers (2011) and points out some suggestions on further studies.
\end{abstract}

Keywords: polysemous phrasal verbs, cognitive linguistics theory, second language acquisition

\section{Introduction}

Cognitive linguistics has constantly been developed internationally and domestically since 1980s, which primarily focused on exploring the theory of cognitive linguistics and using these theories to describe the specific language such as English and Chinese. The interface research between cognitive linguistics and second language acquisition in recent years has aroused concern of linguists both at home and abroad. Researchers review cognitive linguistics as theoretical guidance, making a lot of achievements in the field of second language acquisition, mainly including the following five aspects: (1) the acquisition of English tenses (e.g., Cook-Gumperz \& Kyratzis, 2001); (2) the prototype in English grammar structure (e.g., Hopper, 2001); (3) the second language acquisition of English syntactic knowledge (e.g., Harrington, 2002); (4) the acquisition of metaphor and idioms (e.g., Kovecses \& Szabo, 1996); (5) the acquisition of second language vocabulary (e.g., Csabi, 2004) (LI \& CAI, 2008). Vocabulary teaching and learning in second language teaching and research has

\footnotetext{
* Acknowledgements: This work was supported by the National Social Science Fund of China (Grant number: 13BYY083), Humanities and Social Sciences Fund of Ministry of Education, China (Grant number: 11YJA740059). the Scientific Research Fund for Imported Talents of Guangdong University of Foreign Studies (GWTP-YJ-2015-07).

LU Zhi, Professor, Guangdong Collaborative Innovation Center for Language Research and Services, Guangdong University of Foreign Studies, E-mail address: luzhi@gdufs.edu.cn.

SUN Juan, Master, Faculty of Foreign Languages, Ningbo University, E-mail address: fls_sunjuan@163.com.
} 
not received enough attention for a long time until the late 1980s, which thanks to the development and application of cognitive linguistics theory. We can say that cognitive linguistics pushes the development of vocabulary from the edge into the center of research in this field, which also has greatly deepened and expanded the understanding of vocabulary structure and nature, thus becoming an important driving force in the research of second language vocabulary teaching (Hatch \& Brown, 1995).

According to the definition in Longman Dictionary of Contemporary English (1995), phrasal verb is comprised of a single verb and an adverb or a preposition, which is used as a verb phrase, such as set off, look after. Phrasal verb is an important part of modern English. The use of phrasal verbs in English is extremely common, and it is a standard feature of English fluency. For second language (L2) learners of English, phrasal verbs pose numerous difficulties. One challenge is highlighted in the following definition from The American Heritage Dictionary of Phrasal Verbs (2005): A phrasal verb is a combination of an ordinary verb and a preposition or an adverbial particle that has at least one particular meaning that is not predictable from the combined literal meanings of the verb and the preposition or particle. The issue of unpredictability is obviously a troublesome one for learners of English (White, 2012). The meaning of phrasal verbs is not the simple addition of each component, which is usually unpredictable; phrasal verbs on the one hand are ambiguity. A phrasal verb may have a variety of meanings; more phrasal verbs may have the same or similar meaning. On the other hand, when we use it, its subject and object are often subject to the conditions of collocation. These features of phrasal verbs multiply the difficulties of foreign language learners. Traditional semantic approaches of the meanings of verb particle constructions generally consider them to be arbitrary and idiosyncratic (Neagu, 2007, p. 123). Therefore, the teaching methods of polysemous words are simple mechanical rote manner, or just guessing the meaning based on the context. Thus, the teaching effect is far from being satisfied. With the in-depth study of language, especially the rise and flourish of cognitive linguistics, people come to realize that the meanings of lexical semantics are systematic and the relationship between the items of one polysemy is cognitively motivated. Foreign scholars apply cognitive linguistics to the teaching of second language vocabulary, showing that the use of cognitive methodology to improve the students' metaphor awareness is beneficial to second language acquisition (e.g., Boers \& Demecheleer, 1997; Boers, 2000a; Boers, 2000b; Kovecses, 2001; Requejo \& Diaz, 2008; Yasuda, 2010; Tyler, 2011; White, 2012). The following passage will focus on theoretical and empirical studies on phrasal verbs and then analyze the drawbacks of these studies, putting forward the further studies.

\section{Theoretical Studies on Phrasal Verbs}

Theoretical studies on phrasal verbs mainly include the following three aspects, namely, syntactic approaches to phrasal verbs, semantic approaches to phrasal verbs, and cognitive approaches to phrasal verbs.

\section{Syntactic Approaches to Phrasal Verbs}

Traditional researches on phrasal verbs, mostly start from structuralism, primarily focusing on its syntactic features. The first study on phrasal verbs can be traced back to 1919, the publication of Van Dongen's article He Puts On His Hat And He Puts His Hat On. This paper analyzes the surface structure of the sentence and mainly discusses the position of particles. Among those who study English phrasal verbs from the perspective of syntactic nature, Quirk's Comprehensive Grammar of the English Language is the most representative one. Phrasal verbs are called as “multi-word verb”, composed of "verb + adverb”, "verb + preposition”, and "verb + 
preposition + adverb", representing an indivisible whole concept. Based on whether verbs are intransitive or transitive, and whether verbs and particles can be separated or not, the particles in the phrasal verbs are divided into three categories by Quirk et al.

Seidle (1980) divides phrasal verbs into six categories from the perspective of the syntax. She regards the property of all the multi-verbs as transitive and intransitive, namely: (1) intransitive + particle, e.g.: slow down; (2) intransitive + preposition, e.g.: count on someone / something; (3) intransitive + particle + preposition, e.g.: put up with someone / something; (4) transitive + particle, e.g.: take someone off; (5) transitive + preposition, e.g.: talk someone into something ; (6) transitive+ particle + preposition, e.g.: put something down to something.

Syntactic approaches to phrasal verbs at home have begun since 1980s. The phenomenon of phrasal verb also arouses the interest of many scholars, including WANG Rong-pei, LU Guo-qiang, and ZHANG Dao-zhen who emphasize on the stability of its structures and syntactic function. LUO Ting-liang (1985) attaches great importance to the syntactic function of phrasal verbs. LAI An-fang and DONG Jin-wei (1995) divides the phrasal verbs into three subgroups: verb+ adverb; verb + preposition; and verb + adverb + preposition. WANG (1997) regards phrasal verbs as "the sinews of our English language” (WANG, 1997, p. 18).

CHENG Jie (2010) proposes a new method of phrasal verbs from the perspective of syntax-VCP analysis. VCP analysis is based on the latest achievements of modern syntax theory development, regarding the phase theory as theoretical background, using the V-Bar Pied-piping Hypothesis as well as conventional displacement of the verbs to derive two structures separately, namely the continuous usage and the split usage of English phrasal verbs, which gives a relatively simple, systematic and comprehensive explanation of the main features of English syntax and semantics of phrasal verbs.

Studies belong to the syntactic approaches pay great attention to the structure of phrasal verbs and make it easier for foreign language learners to grasp the structure, boosting people to realize the importance of phrasal verbs. These approaches, on one hand, overemphasize the significance of the learning of structures; on the other hand, however, give little care to the meanings' learning which is also very essential for foreign language learners. Needless to say, there were little effective learning strategies to master phrasal verbs at this period because of the lack of attention on semantic features of phrasal verbs. Thus, there are still many problems and challenges confronting linguists and scholars.

\section{Semantic Approaches to Phrasal Verbs}

Due to the limitations of structuralism, the vigorous development of researches from the perspective of cognitive semantics gave birth to the prosperity of phrasal verbs research. Later, linguists moved attention towards the semantic study of phrasal verbs. Traditional semantic approaches to the meanings of phrasal verbs generally consider them to be arbitrary and idiosyncratic. According to Fräser (1976), particles do not contribute to the meaning of phrasal verbs. He states explicitly: "we are assuming here that there is no need to associate any semantic feature with the particle, only phonological and syntactic features”(Fräser, 1976, p. 77). Besides, he assumes that there is no obvious way of predicting the effect that the addition of the particle has no meaning in a verb particle construction, which in his view is an idiom, and components of idioms have no meaning. This assumption can be accounted for by his belief that the loss of literal, concrete meaning of a particle implies the loss of meaning altogether (Neagu, 2007, p. 123). 
Bolinger (1971) believes that the phrasal verb is a gradient category. In his book, he points out position movement and result landmark are the two features that particle in the core meaning of the phrasal verb must contain. Bolinger has a deep discussion on the semantic features of particles in which he specifies that the feature of the particles which can appear in phrasal verbs is their ability to convey, depending on the situation, either a directional or resultant meaning. He also gives an analysis on the relationship between the position of the particle and the meaning focus. Take do over the dress and do the dress over as examples, in the first sentence, the particles over undertakes an integral part of the verb while in the second one, it becomes an ordinary verb. Bolinger's study contributes a lot to the particle research, but it still subjects to the framework of generative grammar, assuming that language can be generated by finite, discrete grammar.

Sinclair (1989) finds a correlation between phrasal verbs which have the same particles. In his book Corpus, Concordance, Collocation, he systematically describes the meaning of phrasal verbs. In this book, he lists 38 common verbs, and notes that these verbs can be composed of a large number of phrasal verbs when used in conjunction with particles.

Side (1990) mainly focuses on the particles of phrasal verbs. He observes that the meaning of particles could be part meaning of phrasal verbs, and in some cases, the particles may carry more semantic weight than the verb component in the phrasal verbs. Take "bog off" as an example, "off” bears the main communicative function, but having no relationship with "bog”.

Compared with the scholars who study phrasal verbs from the point of structuralism, they do make obvious progress in researching the semantic meaning of phrasal verbs. That is to say, in some situation, particle carries more semantic weight than that of a verb in one phrasal verb. What's more, they realize the great importance of particles in phrasal verbs, which provides a better visual for cognitive linguists. However, they failed to do a further research on how the particles work in common in phrasal verbs and did not give a full understanding of the connections between particles and the whole meaning of phrasal verbs.

\section{Cognitive Approaches to Phrasal Verbs}

Cognitive linguistics bases on the theory of language use, having a significant impact in the field of applied research such as language acquisition, foreign language learning as well as foreign language education. Cognitive linguistics and socio-cultural theory provide a new perspective for the teaching of phrasal verbs. The main representatives are Lindner (1981), Morgan (1997), Gries (1999), and Hampe (2000).

Lindner's doctoral thesis A Lexico-Semantic Analysis of Verb-Particle Constructions with Up and Out opens a full attention of phrasal verbs research. She analyzes the corpus including more than 1,800 phrasal verbs with UP and OUT, which suggests that phrasal verbs, such as pass out, turn up, can be semantically analyzed. She also demonstrates the systematic connections of each item in a phrasal verb, arguing that all the items of phrasal verbs sharing the same particles, literal or metaphoric, are correlated with one image schema, influencing the whole meaning of phrasal verbs.

Inspired by Lindner's study, Morgan (1997) makes a deeper explanation to the metaphorical extension of phrasal verbs. Morgan points out that there are four possible metaphorical extensions after the investigation of the phrasal verb "figure out” (see Table 1). 
Table 1

Metaphorical Extensions of the Particle "out"

\begin{tabular}{|l|l|l|}
\hline Verb & Particle & Example \\
\hline Literal & Literal & I took the mug out of the box. \\
\hline Metaphorical & Literal & We fished out the ring from the bowl. \\
\hline Literal & Metaphorical & He handed out the brochures. \\
\hline Metaphorical & Metaphorical & I picked out a name for the baby. \\
\hline
\end{tabular}

In the phrasal verb "figure out”, the particle "out” reflects the existence of a container by meanings of literal, metaphor, metonymy, or otherwise manners. As he believed, the metaphorical extension of the phrasal verb "figure out" can be analyzed as follows:

(1)figure = "reach solution by thinking" (from THINKING IS CALCULATING)

(2)out = "not within boundaries of container" (from A PROBLEM IS A LOCKED CONTAINER)

(3) figure out = "make a solution cognitively accessible by thinking"

(4) ACCESSIBLE/VISIBLE IS OUT + KNOWING IS SEEING = "cause something to be known by thinking about it"

Gries (1999) studies the position of transitive phrasal verbs and particles from the perspective of cognition. There are mainly two possible positions of particles in a transitive phrasal verb (see Table 2):

Table 2

Two possibilities of placement of the particle by Gries (1997)

\begin{tabular}{|l|l|l|}
\hline Construction 1 & Post-verb position & He picked up a pencil. \\
\hline Construction 2 & Post- DO position & He picked the pencil up. \\
\hline
\end{tabular}

He proposes that the two structural possibilities are the post-verb position (construction 1) and the post-DO (direct object) position (construction 2). He argues that consciousness principle is the deeper principle that determines the placement of particles. Just as the above two sentences: "Construction 1 will be preferred with objects requiring a high amount of consciousness and construction 2 will be preferred with objects requiring none or only a limited amount of consciousness for their processing”(Gries, 1999, p. 64).

Hampe (2000) examines the fifth case of forming metaphor based on the meaning extending of phrasal verbs. After the analysis of "face up to", he argues that before the formation of phrasal verb "to face up to", the verb "to face" has already become a figurative one (face metonymically stand for the whole person). What is more, there exists double metaphor extension in the formation from "to face" to "to face up to". He says that it is a common property of particles that more than one conceptual metaphor stimulates at the same time. With respect to the classification described in traditional research, it has a deeper study on the metaphor of the meaning formation of phrasal verbs, which reveals that the metaphorical extension of verbs and particles contribute to the overall sense of phrasal verbs.

Studies at this period of time at home also have a rapid development. SHU Ding-fang and TANG Ben-qing (2002) based on the traditional metaphoric theory focus on discussing the nature and understanding of metaphor. HE Xue-de and HUANG Tao (2005) studies the most frequency particle "up". According to the image and the

\footnotetext{
${ }^{1}$ See Morgan (1997), p. 335.
} 
image schema of "up" in theoretical background, he believes that the semantic meaning of particle is analyzable in the whole phrasal verb and its basic meaning has a relationship with things motion from junior to senior, or from the lower to the higher. The cognitive linguistic analysis toward the semantics of "up" helps learners and users to master and use the phrasal verbs with up in an easier way.

WANG Zhao-pei (2006) combines metaphor and conceptual blending theory and proposes a new model to explain the semantic formation of English phrasal verbs. In his view, the semantic formation of phrasal verbs experiences four processes, namely the metaphorization process, the meaning matching process, the selecting projection process, and the significance integration process. In the process of constant use and development of language, it gradually formed its relatively fixed and highly idiomatic semantics, finally solidifying in the language. This mode helps language learners with a good understanding of the idiomatic semantics of English phrasal verbs and stylistic features as well as a fine grasp of their usage context.

LONG Shao-yun (2008) points out that particles play a vital role in the semantic formation and expansion of phrasal verbs. This paper explores into the cognitive motivation of the sense formation and expansion in the particle "UP”, with the principles of prototype, family resemblance, image schema, metaphor, combining people's biological, psychological, and social experience with the understanding of verb senses and patterns. It has a concrete interpretation about the principles of motivation in the formation of idioms in order to provide a new approach to the understanding and use of English idioms (LONG, 2008, p. 79).

The cognitive studies on phrasal verbs focus on the semantic meaning of particles as well as its correlation of each item, analyzing their semantics from cognitive perspective. These studies point out that the particles of phrasal verbs may carry more meanings than the verbs, which play an important role in analyzing the overall meanings of phrasal verbs especially the sense expansion from the cognitive linguistics, providing enlightenment on the acquisition of English phrasal verbs, especially the English polysemous phrasal verbs, which was once viewed as arbitrary and unanalyzable before. Thus, the rapid progress of studies on phrasal verbs from the cognitive linguistics stimulate scholars to apply the theory of cognitive linguistics to the foreign language learning of phrasal verbs, which in turn help to improve the teaching methods and reduce the pressure of language learning.

\section{Empirical Studies on Foreign Language Teaching}

\section{Empirical Studies on Polysemy Teaching}

Boers and Demecheleer (1997) explores the teaching methods of polysemous preposition from the perspective of cognitive semantics approach based on the theory that the figurative senses of a preposition are extended from its spatial senses through conceptual metaphors. The research shows that the cognitive semantic analyses of prepositions could be used to anticipate comprehension problems and help to understand the unfamiliar figurative senses.

Tyler and Evans (2004) analyzes the cognitive motivation between the multiple senses of "over", illustrating the explicit teaching methods of "over" to the second language teachers. He points out that the method enables teachers to help the learners study the semantic systems of "over" better, which can effectively avoid the route-learning of its multiple meanings. Unfortunately, they do not prove their method proposed by empirical research. 
Morimoto and Loewen (2007) investigates the effectiveness of two types of instruction —image-schema-based instruction (ISBI) and translation-based instruction (TBI)—on the acquisition of second language (L2) polysemous words. Fifty-eight high school learners of English were divided into two treatment groups (ISBI and TBI) and a control group. In order to examine the effectiveness of instruction, they did a pre-test and then post-test 1 two days later as well as post-test 2 two weeks later. The results showed that ISBI tended to be as effective as TBI, except in one case where ISBI was significantly more effective than TBI. This study suggests that image-schema from the field of cognitive semantics can serve as a pedagogical devise in teaching L2 polysemous words (Morimoto \& Loewen, 2007, p. 347).

Tyler (2011) analyzes in detail the prepositions “to, for, at” with a cognitive linguistic approach and examines its effectiveness of this method in teaching prepositions of "to, for, at" through empirical studies. Research shows that there exists significant difference between the pre-test and post-test and students who receive the teaching methodology from the perspective of cognition have gotten great improvement in the comprehension of the preposition meaning.

Under the influence of foreign studies, scholars at home also did a lot of empirical researches on polysemies. QU Yun-hua and ZHANG Jian-li (2005) combines with the cognitive linguistics theory, taking the polysemy "before" as an example and analyzing the acquisition of semantic system of Chinese college students. It shows that in the intermediate stage of college English learning, although the amount of vocabulary greatly increased, the amount of multiple senses at a standstill, which is consistent with the research of YU Jue (2011). CHEN Xiao-xiang and XU Yin (2009) compares the effectiveness of semantic teaching method based on image-schema with the teaching method based on translation to the three polysemous prepositions “on, over, and above”, which shows that the former method has a positive influence on learning of English polysemous preposition.

\section{Empirical Studies on Phrasal Verbs Teaching}

Cognitive linguistics and socio-cultural theory provide a new perspective for the teaching of phrasal verbs. Kovecses and Szabo (1996) were the first to investigate the impact of CM groupings on L2 idiom learning. Their main aim was to see whether presentation of L2 vocabulary in terms of CM groupings would lead to better vocabulary memorization than the simple presentation of words accompanied by their L1 equivalents. Hungarian adult intermediate-level learners of English were taught phrasal verbs with “up” and “down”. Half of the participants were presented with the Hungarian equivalents of the phrasal verbs and the other half with the underlying CMs as well. The group that had received the CM instruction gave a higher percentage of correct responses than the other group as far as the taught phrasal verbs were concerned (Skoufaki, 2008, p. 103).

Boers (2000a) verifies the role of conceptual metaphor in vocabulary teaching with three experiments. He also points out that the lexical organization along metaphoric themes or source domains can facilitate retention of unfamiliar figurative expressions and it is necessary to enhance learners' conceptual metaphor awareness in the process of vocabulary learning and teaching.

Liao and Fukuya investigates the avoidance of English phrasal verbs by Chinese learners. Six groups of Chinese learners (intermediate and advanced; a total of 70) took one of three tests (multiple-choice, translation, or recall), which included literal and figurative phrasal verbs, while 15 native speakers took the multiple-choice test. The results show that three factors (proficiency level, phrasal verb type, and test type) affect learners' avoidance 
of phrasal verbs. The authors speculate that the differences between first and second languages and the semantic difficulty of phrasal verbs may be reasons for the learners' avoidance. Incorporating the findings of three previous studies, this study claims that learners' phrasal-verb avoidance behavior is a manifestation of interlanguage development (Liao \& Fukuya, 2004, p.193).

Requejo and Diaz (2008) apply some recent findings about the meaning of prepositions in cognitive linguistics to some phrasal verbs in ESP, namely Medical and Computer English. This paper mainly focuses on the phrasal verbs with "in" and "out", explicitly exploring each phrasal verb with an image-schema. The result shows that the understanding of prepositions contributes to the comprehension of phrasal verbs.

Yasuda (2010) mainly examines whether enhancing the awareness of orientational metaphors of particles facilitates acquisition of phrasal verbs by Japanese learners who learn English as a foreign language. The students in the control group learned a set of phrasal verbs through traditional methods, while the students in the experimental group received the same input through a cognitive linguistic approach. Then, students in the two groups were required to fill the missing adverbial particles of phrasal verbs. The tests show that the students in the experimental group outperform those in the control group, which indicates that when the target idioms are not stored as a unit in learners' mental lexicon, learners who are aware of conceptual metaphors may rely on metaphorical thought to produce an appropriate adverbial particle. This highlights the implications that EFL learners explicitly taught about the notion of orientational metaphors before they can actively comprehend and produce appreciate phrasal verbs (Yasuda, 2010, p. 250).

White (2012) did an empirical research on the acquisition of phrasal verbs based on the cognitive linguistics and socio-cultural theory. It proposes a pedagogical approach which includes five steps to encourage students to tap their own creativity so that to conceptually motivate student-collected examples of phrasal verbs, namely, the first step is to offer learners a new way to view phrasal verbs; the second step is to ask students to go phrasal verb hunting; the third step is the discussion of the meaning of phrasal verbs; the fourth step is to ask students to express those meanings through drawings; the fifth step is sharing drawings. It shows that students made changes (from the pre-instruction task to the post-instruction task) in how they explained phrasal verbs and that most students valued completing the steps of the approach suggest future attempts at teaching phrasal verbs with emphasis on conceptualization are worthwhile (White, 2012, pp. 432-433). Furthermore, it points out that in the recent design of textbook writing, the organized classification of phrasal verbs is benefit to relieve the burden of memorization of English phrasal verbs, whereas research on how to teach these multi-meanings is far from enough.

Empirical researches on English phrasal verbs from the perspective of cognitive linguistics show consistence in the effectiveness of teaching phrasal verbs combined with cognition. The students in experimental group learning phrasal verbs with a cognitive linguistic approach have an advantage over the students in control group who receive traditional teaching methodology on memorization and comprehension.

Influenced by the foreign studies, domestic scholars SHEN Yu-gang (2002) took native speakers of Chinese as the subjects and did an empirical research on the effectiveness of metaphor awareness on the acquisition of English phrasal verbs based on experimental methods of Kovecses (1996) and Boers (2000a). It shows that enhanced metaphor awareness facilitates the acquisition of English phrasal verbs.

The ambiguity of English phrasal verbs has posed great difficulty for foreign language learners who lack 
phrasal verbs in their mother tongue such as Chinese-speaking students. Therefore, LIU Shi-li (2006) investigates and analyzes the misuses of Chinese learners on phrasal verbs and ZHANG Bin (2007) uses multiple-choices test and interview to study Chinese learners' avoidance of two different types of phrasal verbs. The result shows that most of the intermediate learners tend to avoid using English phrasal verbs. What is more, both intermediate and advanced learners are more likely to avoid figurative phrasal verbs. According to LIU, it is the consequence of semantic features of phrasal verbs, English proficiency of learners, language learning environment as well as the insurance policy taken by learners and so on. GUO Wei (2013) points out that Chinese learners and American native speakers show great differences in using English phrasal verbs. The inner complexity of English forms the major factor in increasing the difficulty of learning phrasal verbs.

Apart from the use of phrasal verbs in written English, YU Jue (2011) uses the spoken English corpus of Chinese learners to investigate the usage of phrasal verbs in spoken English through quantitative research and microscopic analysis. The study shows that students' ability to use phrasal verbs strengthen with the improvement of English proficiency, but at the stage where English proficiency goes from the intermediate level to a higher level, learners' ability stagnate in using phrasal verbs. He makes a comparative analysis of the British national corpus and spoken English corpus of Chinese learners in using relative phrasal verbs, showing that Chinese English majors may face the phenomenon of misusing particles or verbs, collocation deviation, syntax defect as well as simplification.

WEI Mei (2014) studies the conceptual teaching method to English phrasal verbs' learning from the perspective of cognitive linguistics and sociocultural theory. Forty-five English majors attended this empirical research. Students in the experimental group understand the conception of phrasal verbs by drawing and discussing, whereas students in the control group receive the same input by route learning. Studies show that conceptual teaching method has a positive effect on the learning of phrasal verbs and it arouses the comprehension of phrasal verbs in the process of utilizing conceptual tools such as schema and language and deepens internalization and memorization as well as improving the learning autonomy and thinking activity.

WEN Wei-xia and LI Hai-ying (2014) explores the basic and extended meaning of English phrasal verbs according to the image-schema and metaphor theory in cognitive linguistics. The study shows that image schema and metaphor provide a new perspective for the understanding of polysemous phrasal verbs, which helps to learn the multiple meanings of phrasal verbs systematically for foreign language learners.

\section{Conclusion}

Compared with the traditional studies on English polysemous phrasal verbs, there is no doubt that researches of phrasal verbs based on cognitive linguistic theory show greater effectiveness on both teaching and learning for foreign language learners of English. With the rise and vigorous development of cognitive linguistics, cognitive linguists (e.g. Lakoff \& Johnson, 1980; Brugman, 1981; Fillmore, 1982; Langacker, 1987; Sweetser, 1990; Lakoff, 1987; Boers \& Demecheleer, 1998 ; Ravin \& Leacock, 2000) believe that different usages of polysemies are connected by the complex network of the relationship between metaphor and metonymy. Metaphors play a pivotal role in cognitive linguistics. Empirical studies both abroad and at home based on metaphor and image-schema show that it is beneficial for learners to enhance and strengthen the comprehension and retention of polysemous phrasal verbs. While among these empirical studies, there also exist many drawbacks which we 
can not ignore: (1) There should be proper pre-test before the tests; (2) Students in control group and experimental group of some studies receive different instructional treatment. These should involve a similar investment of time and effort on the part of the learners, and a similar amount of input to stimulate that investment; (3) The format of post-test should be consistent with that in the instruction you design. For example, it would be more effective if you test the form of vocabulary after guiding subjects to focus on the form during the instruction; (4) A large amount of studies lack delayed post-test which is also very important to test the effectiveness of studies; (5) In the gap-filling tests, it is not proper if the range of option is too small. The chance factor is substantial if the test consists of relatively few items. Besides the above problems, what is more, studies at home should be considered with the condition of Chinese learners.

Therefore, the further study should explore intrinsic factors impeding Chinese learners in learning phrasal verbs so as to guide the English teaching, discussing the systematization between multiple meanings of one phrasal verb and demonstrating that the semantic extension is not arbitrary but rational. Thus, for foreign language learners, to some extent, it can reduce stress and help to strengthen memory and understanding of phrasal verbs. Above all, the empirical study should closely integrated with teaching in order to effectively apply cognitive linguistic theory into English teaching and learning, testing and verifying the effectiveness of it in foreign language teaching, which is helpful to raise the quality and standard as well as guide the English teaching.

\section{References}

Boers, F. (2000a). Metaphor awareness and vocabulary retention. Applied Linguistics,21(4), 553-571.

Boers, F. (2000b). Enhancing metaphoric awareness in specialized reading. English for Specific Purposes,19, 137-147.

Boers, F. (2011). Cognitive semantic ways of teaching figurative phrases: An assessment. In F. Gonzálvez García, M. S. Peña Cervel, and L. Pérez Hernández (Eds.), Metaphor and metonymy revisited beyond the contemporary theory of metaphor: Recent developments and application. Berlin/New York: Mouton de Gruyter.

Fräser, B. (1976). The verb-particle combination in English. In Taishukan studies in modern linguistics. New York: Academic Press.

Gries, S. (1999). Particle movement: A cognitive and functional approach. Cognitive Linguistics, 10(2), 105-145.

Hampe, B. (2000) Facing up to the meaning of “Face up to”. In A. Foolen and F. van der Leek (Eds.), Constructions in cognitive linguistics (81-101). Amsterdam, Philadelphia: Benjamins.

Hatch, E., \& Brown, C. (1995). Vocabulary, semantics and language education. Cambridge: Cambridge University Press.

Liao, Y. D., \& Fukuya, Y. J. (2004). Avoidance of phrasal verbs: The case of Chinese learners of English. Language Learning, 4(2), 193-226.

Morgan, P. S. (1997). Figuring out figure out: Metaphor and the semantics of the English verb-particle construction. Cognitive Linguistics, 8(4), 327-357.

Morimoto, S., \& Loewen, S. (2007). A comparison of the effects of image-schema-based instruction and translation-based instruction on the acquisition of L2 polysemous words. Language Teaching Research 11, 347-372.

Neagu, M. (2007). English verb particles and their acquisition. A cognitive approach. RESLA, 20, 121-138.

Skoufaki, S. (2008). Conceptual metaphor meaning clues in two idiom presentation methods. In F. Boers and S. Lindstromberg (Eds), Cognitive linguistic approaches to teaching vocabulary and phraseology. Berlin: Walter de Gruyter.

White, B. J. (2012). A conceptual approach to the instruction of phrasal verbs. The Modern Language Journal, 96, 419-438.

Yasuda, S. (2010). Learning phrasal herbs through conceptual metaphors: A case of Japanese EFL learners. TESOL OUARTERL, 44(2), 250-273.

Longman Dictionary of Contemporary English. (1995). Beijing: Foreign Language Teaching and Research Press Pub.

The American Heritage Dictionary of Phrasal Verbs. (2005). Boston : Houghton Mifflin Harcourt.

LI, J., \& CAI, J. T. (2008). 认知语言学角度的英语空间介词习得研究 (Cognitive linguistics and the acquisition of English spatial prepositions by Chinese EFL). 现代外语, 31(2), 185-193. 
LONG, S.Y. (2008). UP语义伸延的认知视角 (The cognitive perspective of the semantical expansion of the particle UP). 四/I 外语学院学报, 24(3), 79-83.

WANG, R. P. (1997). 英语的短语动词 (English phrasal verbs). 外语与外语教学, (4), 18-23. 